\title{
Ueber Philonthus temporalis Muls., tenuicornis Muls. und addendus Sharp.
}

Philonthus temporalis Muls. (Opuse. entom. II. p. 94), bisher nicht in Deutschland nachgewiesen, ist mir in den letzten Jahren einzeln aus Schlesien (Gerhard), Tyrol (Kahr), Rheinland (Eichhoff) zugekommen. Der Käfer mag weniger selten als bisher mit Phil. lucens verwechselt sein. Von demselben unterscheidet er sich bei einiger Uebung leicht durch den gröfseren Kopf, welcher durch seine eckige Gestalt mehr an den des aeneus erinnert, während der rundliche Kopf des lucens nur etwa so klein wie beim politus ist. Die Flügeldecken des temporalis sind etwas länger, die Hinterleibssegmente oben und unten noch lebhafter farbenschillernd als beim lucens, etwas weitläufiger und kräftiger punktirt. Vom aeneus unterscheidet sich der temporalis leicht durch die, in der Mitte nicht kielartig vorgezogene eingedrückte Linie an der Basis der vorderen Hinterleibssegmente (ähnlich wie bei tenuicornis Muls.), den kleineren Kopf, grünlich erzfarbene Flügeldecken etc. Der temporalis ist kleiner als aeneus, gröfser als tenuicornis, welcher feinere Fübler besitzt.

Philonthus tenuicornis Muls. ist auch von H. Fufs bei Cleve aufgefunden worden; aulser an den von H. Pfarrer Scriba angegebenen Merkmalen (Berl. Ent. Zeitschr. X. p. 293) ist der Käfer daran leicht zu erkennen, dafs er merklich kleiner als Phil. carbonarius, aeneus etc. ist, und dafs die vertiefte Linie an der Basis der oberen ersten Hinterleibssegmente bei ihm in der Mitte keinen ausspringenden Winkel oder kielartiges Längsfälıchen bildet, sondern ununterbrochen fortläuft. Nach $\mathrm{H}$. Crotch ist der tenuicornis weit in England verbreitet.

Philonthus addendus Sharp ist nach brieflicher Mittheilung von H. Crotch aus Edingburgh eine dritte hierher gehörige Art, welche sich nach ihm wahrscheinlich auch in Deutschland finden wird. Diese besitzt, wie aeneus und succicola Thoms. (carbonarius Er.) die kielartig vorspringende Linie in der Mitte der vorderen Hinterleibssegmente, weicht aber von ihnen durch schlankere Fühler mit quadratischen Gliedern ab.

Von meinem Phil. punctiventris habe ich nachlräglich ein Stück aus den Piemonteser Alpen von Ghiliani, ein Stück aus den rhaethischen Alpen von Dr. Stierlin als rhaeticus Stierl. erhalten. Bei dieser Art verläuft die eingedrückte Linie an der Basis der vorderen oberen Hinterleibssegmente fast ganz gerade. Dr. G. Kraatz. 


\section{$2 \mathrm{BHL}$ Biodiversity Heritage Library}

Kraatz, G. 1868. "Ueber Philonthus temporalis Muls., tenuicornis Muls. und addendus Sharp." Berliner entomologische Zeitschrift / herausgegeben von dem Entomologischen Vereine in Berlin 12(3), 351-351.

https://doi.org/10.1002/mmnd.18680120318.

View This Item Online: $\underline{\text { https://www.biodiversitylibrary.org/item/34406 }}$

DOI: https://doi.org/10.1002/mmnd.18680120318

Permalink: https://www.biodiversitylibrary.org/partpdf/210140

\section{Holding Institution}

Smithsonian Libraries

\section{Sponsored by}

Smithsonian

\section{Copyright \& Reuse}

Copyright Status: Public domain. The BHL considers that this work is no longer under copyright protection.

This document was created from content at the Biodiversity Heritage Library, the world's largest open access digital library for biodiversity literature and archives. Visit BHL at https://www.biodiversitylibrary.org. 